nephron

Practice
Nephron 2018;140:24-30

DOI: $10.1159 / 000490202$
Received: January 24, 2018

Accepted after revision: May 21, 2018

Published online: June 26, 2018

\title{
Patterns of Erythropoiesis-Stimulating Agent Use in European Hemodialysis Patients: The Dialysis Outcomes and Practice Patterns Study
}

\author{
Douglas S. Fuller ${ }^{a}$ Bruce M. Robinson ${ }^{a, b}$ Francesco Locatellic \\ Ronald L. Pisoni ${ }^{\mathrm{a}}$ \\ ${ }^{a}$ Arbor Research Collaborative for Health, Ann Arbor, MI, USA; ${ }^{b}$ Department of Internal Medicine, University of \\ Michigan, Ann Arbor, MI, USA; ' Department of Nephrology, Alessandro Manzoni Hospital, Lecco, Italy
}

\section{Keywords}

Hemodialysis · Erythropoiesis-stimulating agent · Practice patterns $\cdot$ Anemia

\begin{abstract}
Background: Clinicians providing dialysis care have numerous erythropoiesis-stimulating agents (ESAs) available for treating anemia. We sought to provide a contemporary description of ESA types used in hemodialysis (HD) settings in nine European countries. Methods: Our study uses Dialysis Outcomes and Practice Patterns Study phase 5 (20122015) data from nine European countries (Belgium, France, Germany, Italy, Russia, Spain, Sweden, Turkey, and the United Kingdom). A total of 164 facilities and 3,281 patients contributed cross-sectional data. ESA types captured included short-acting epoetins (e.g., epoetin alfa, beta, etc., including biosimilars), darbepoetin alfa, and continuous erythropoietin receptor agonist (CERA; methoxy polyethylene glycol-epoetin beta). Results: We observed broad variability across countries in prescription of ESA types: prescription of epoetin alfa or epoetin beta ranged from $22 \%$ (France) to $78 \%$ (Russia), darbepoetin alfa prescription ranged from 13\% (Russia) to 53\% (UK), and CERA prescription ranged from $<3 \%$ (Sweden) to 26\% (France). Prescription of different ESA types varied substantially within some European countries
\end{abstract}

(c) 2018 S. Karger AG, Basel from 2012-2015 but not across all countries in aggregate. Number of ESA types prescribed by a facility varied from 1, 2,3 , or 4 different ESA types in 32, 40,21, and 8\% of facilities, respectively. No differences were seen in the unadjusted distributions of achieved hemoglobin values by ESA type. Conclusion: A variety of short- and long-acting ESAs are commonly used in European HD facilities to maintain hemoglobin at remarkably similar levels with each ESA type. The availability of numerous ESA options for managing anemia has allowed European providers to optimize anemia management according to the particular circumstances of each patient.

(c) 2018 S. Karger AG, Basel

\section{Introduction}

Anemia is a common complication seen in patients with end-stage kidney disease on hemodialysis (HD) [1]. During the early years of HD treatment, patients required frequent red blood cell transfusions to maintain target hemoglobin levels. However, in 1989, the first human re-

The work was conducted at Arbor Research Collaborative for Health, Ann Arbor, MI, USA.
Mr. Douglas S. Fuller

Arbor Research Collaborative for Health

340 E Huron St. No. 300

Ann Arbor, MI 48104 (USA)

E-Mail doug.fuller@ arborresearch.org 
combinant erythropoiesis-stimulating agent (ESA), epoetin alfa [2], was introduced commercially and quickly became a key therapeutic agent for treating anemia in maintenance HD patients. Epoetin beta [3] received European marketing authorization in 1990 [4]. Posttranslational modifications to these initial ESAs were developed to provide longer duration of action, such as darbepoetin alfa, introduced worldwide in 2001 [5], and methoxy polyethylene glycol-epoetin beta (alternatively and henceforth, continuous erythropoietin receptor agonist [CERA]), introduced in Europe in 2007 [6]. Lastly, biosimilar products - biological medicines highly similar to another already approved biological medicine (the "reference medicine") that are approved according to the same standards of pharmaceutical quality, safety, and efficacy that apply to all biological medicines - have been available in Europe since 2007 [7], providing additional choices for managing anemia in HD patients. Thus, clinicians providing HD care have a number of options in their ESA arsenal for treating anemia.

Studies reporting on the variety of ESA types used in Europe are scant. We sought to provide a contemporary description of ESA products used in HD settings in 9 European countries and to provide some information on dose conversions used to support achieved hemoglobin levels.

\section{Methods}

The Dialysis Outcomes and Practice Patterns Study (DOPPS) is a prospective cohort study of center-based, adult chronic HD patients in $>20$ countries ongoing since 1996. Study sites and patients are randomly selected to achieve nationally representative samples in each country. Details on study design and objectives have been published [8-10]. Our study uses DOPPS phase 5 (2012-2015) data from 9 countries in Europe (Belgium, France, Germany, Italy, Russia, Spain, Sweden, Turkey, and the United Kingdom). Overall, 164 facilities and 3,281 patients contributed cross-sectional data for analysis. The interquartile range (IQR; 25th-75th percentiles) for study entry date was May 2012 through October 2013. Additional data from DOPPS phase 4 (2009-2012) were used for longitudinal analyses as described below. The DOPPS maintains ethics committee approvals in all participating countries, and informed consent was collected from all selected study patients.

Hemoglobin and ESA prescription data, including product type (isoform) and dose, were collected for study patients at DOPPS 5 study entry and monthly thereafter in some countries. Product types captured included short-acting epoetin isoforms (e.g., epoetin alfa, beta, delta, zeta, theta, including biosimilars regulated by the European Medicines Agency [EMA] and other copies not authorized by the EMA), darbepoetin alfa, and CERA. The DOPPS 5 surveys did not distinguish ESA biosimilars and copies from their originator drugs. Thus, our characterization of epoetin alfa includes the originator drug, biosimilars regulated by the EMA (e.g., epoetin zeta), and other copies of epoetin alfa not authorized by the EMA. ESA doses were standardized to a per-week (7 days) value and were based upon prescriptions rather than actual amount administered. Doses for short-acting ESAs were additionally stratified by route of administration (intravenous, subcutaneous). Cross-sectional results are provided using patient level and facility aggregated data.

Among patients in 4 countries (Germany, Italy, Spain, UK) for which monthly longitudinal data were available between January 2011 and April 2015, we estimated dose conversion ratios between short-acting ESAs (IV-administered only), darbepoetin alfa, and CERA. These analyses were restricted to patients prescribed the indicated ESA for at least 3 of the 4 months in the respective preor post-conversion periods. The mean of monthly ESA doses during the 4 months prior to the conversion and the mean of monthly ESA doses for months 3-6 after conversion (thereby allowing for a titration period) were used to establish the conversion ratio for each patient. We report the median within-patient conversion ratio across patients, adjusted for within-patient hemoglobin differences between the pre- vs. post-conversion periods.

Hemoglobin levels were reported for all patients included in these analyses at study entry. Cross-sectional patient hemoglobin values were assigned to the ESA type prescribed for the patient at study entry. Hemoglobin distributions by ESA type were estimated using a kernel density plot with normal (Gaussian) weighting.

Data management and statistical analyses were performed using SAS 9.4 (SAS Institute, Inc., Cary, NC, USA).

\section{Results}

The patient level distribution of ESA types by country is shown in Figure 1. We observed broad variability across countries in overall use of ESA types: use of shortacting types (epoetin alfa or epoetin beta) ranged from $22 \%$ (France) to $78 \%$ (Russia); use of darbepoetin alfa ranged from $13 \%$ (Russia) to $53 \%$ (UK); and use of CERA ranged from $<3 \%$ (Sweden) to $26 \%$ (France). Use of other ESAs (e.g., epoetin theta) was highest in Germany and Russia (4 and 3\%, respectively). Intravenous route of administration was $88 \%$ for darbepoetin alfa and CERA, $82 \%$ for epoetin alfa, and $57 \%$ for epoetin beta. Using aggregated longitudinal data available from 6 countries (Belgium, Germany, Italy, Spain, Sweden, and the UK), we observed a trend toward greater use of "other" ESAs (primarily epoetin theta) from 2010 to 2015, driven largely by sharp trends in the distribution of ESA types used in some of the individual countries over this time period (online suppl. Figs. 1, 2, see www.karger. com/doi/10.1159/000490202).

The number and distribution of ESA types reported by DOPPS facilities in Europe are shown in Figure 2. Ap- 


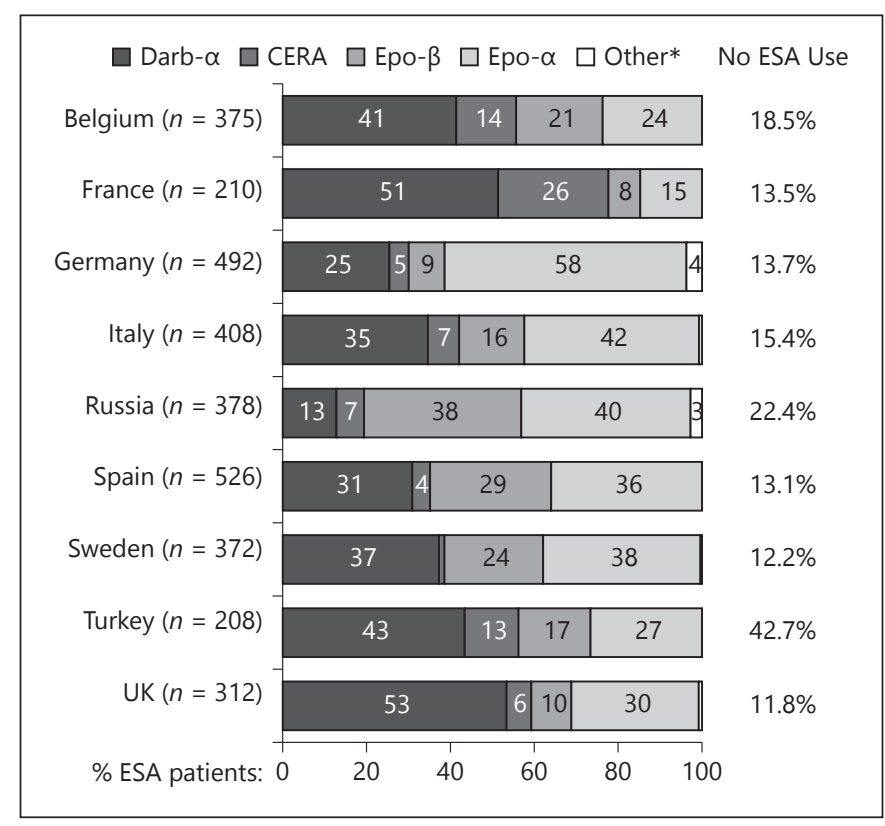

Fig. 1. Patient ESA type distribution at DOPPS 5 study entry, by country. The interquartile range (25th-75th percentiles) for study entry date was May 2012 through October 2013. * "Other" refers to non- $\alpha / \beta$ epoetin forms, primarily epoetin $\theta$. Epo- $\alpha$ includes biosimilars regulated by the EMA and other copies not authorized by the EMA. EMA, European Medicines Agency; DOPPS, Dialysis Outcomes and Practice Patterns Study; CERA, continuous erythropoietin receptor agonist (methoxy polyethylene glycol-epoetin $\beta$ ).

\begin{tabular}{|c|c|c|c|c|c|c|c|}
\hline \multicolumn{8}{|c|}{ Percentage of facilities } \\
\hline 0 & \multicolumn{2}{|l|}{20} & 40 & 60 & 80 & \multicolumn{2}{|c|}{100} \\
\hline & \multicolumn{2}{|c|}{$\square 1 \mathrm{ESA}$} & \multirow{2}{*}{\multicolumn{2}{|c|}{$\frac{\square 2 \text { ESAs } \square 3 \text { ESAs }}{40}$}} & \multicolumn{2}{|l|}{$\square 4$ ESAs } & \\
\hline & \multicolumn{2}{|l|}{32} & & & 21 & 8 & \\
\hline & 1 ESA type & $\%$ & 2 ESA types & $\%$ & \multicolumn{2}{|c|}{3 ESA types } & $\%$ \\
\hline & Darb- $\alpha$ & 42 & Darb- $\alpha /$ Epo- $\alpha$ & 51 & \multicolumn{2}{|c|}{ Darb- $\alpha / E p o-\beta / E p o-\alpha$} & 50 \\
\hline & Epo- $\alpha$ & 31 & Darb- $\alpha /$ CERA & 20 & \multicolumn{2}{|c|}{ Darb- $\alpha /$ CERA/Epo- $\alpha$} & 32 \\
\hline & Epo- $\beta$ & 19 & Еро- $\beta /$ Epo- $\alpha$ & 11 & \multicolumn{2}{|c|}{ Darb- $\alpha /$ CERA/Epo- $\beta$} & 15 \\
\hline \multirow{3}{*}{\multicolumn{2}{|c|}{ CERA }} & 8 & Darb- $\alpha /$ Epo- $\beta$ & 8 & \multirow{3}{*}{\multicolumn{2}{|c|}{ CERA/Epo- $\alpha$}} & 3 \\
\hline & & & CERA/Epo- $\alpha$ & 6 & & & \\
\hline & & & CERA/Epo- $\beta$ & 5 & & & \\
\hline
\end{tabular}

Fig. 2. Combinations of ESA types used by HD facilities $(n=164)$ at DOPPS 5 study entry. The interquartile range (25th-75th percentiles) for study entry date was May 2012 through October 2013. The data table shows relative proportions within combination count type. Epo- $\alpha$ includes biosimilars regulated by the EMA and other copies not authorized by the EMA. EMA, European Medicines Agency; ESA, erythropoiesis-stimulating agent; DOPPS, Dialysis Outcomes and Practice Patterns Study; CERA, continuous erythropoietin receptor agonist (methoxy polyethylene glycol-epoetin $\beta$ ). proximately $32 \%(n=52)$ of facilities reported use of a single ESA type; of these, $42 \%$ reported using darbepoetin alfa, 50\% used short-acting types (either epoetin alfa or epoetin beta), and $8 \%$ used CERA. Use of 2 ESA types was reported by $40 \%$ of facilities $(n=65)$; of these, the most common combinations were epoetin alfa and darbepoetin alfa (51\%) and darbepoetin alfa and CERA (20\%). Three ESA types were used by $21 \%$ of facilities $(n=34)$, and $8 \%$ of facilities $(n=13)$ reported using all 4 ESA types. Across facilities, all possible combinations of epoetin alfa, epoetin beta, darbepoetin alfa, and CERA were observed.

Figure 3 shows the distribution of dosing frequency by ESA type. Epoetin alfa and epoetin beta were most commonly administered 1-3 times per week (95-97\%). For epoetin alfa, median intravenous doses were 8,735 units/week (IQR 5,028-13,914) and 5,572 units/week (IQR 2,998-7,734), when dosed $3 \mathrm{x}$ versus $2 \mathrm{x}$ per week, respectively. For epoetin beta, when dosed $3 \mathrm{x}$ versus 2x per week, median intravenous doses were 9,606 units/ week (IQR 6,000-15,370) and 4,759 units/week (IQR $4,000-7,845)$, respectively. Darbepoetin alfa was most commonly administered weekly (66\%) or biweekly (22\%), with median doses of $132 \mu \mathrm{g} / \mathrm{month}$ (IQR 79-228) and $57 \mu \mathrm{g} /$ month (IQR 37-110), respectively. CERA was most commonly administered monthly (83\%) or biweekly (12\%), with median doses of $109 \mu \mathrm{g} /$ month (IQR 62-159) and $150 \mu \mathrm{g} /$ month (IQR 109-215), respectively. Overall ESA dose distributions by type are presented in Table 1 .

ESA type switching was fairly uncommon among patients followed for at least 6 months, with only 77 conversions identified. The median within-patient conversion ratio between short-acting ESAs and darbepoetin alfa $(n=47)$ was 206 (iv) epoetin units to $1 \mu \mathrm{g}$ darbepoetin alfa (IQR 168-321), adjusted for the difference in hemoglobin values before and after conversion for each patient. The median adjusted conversion ratio between short-acting ESA and CERA $(n=21)$ was slightly higher at 255 (iv) epoetin units to $1 \mu \mathrm{g}$ CERA (IQR 167-390). The median adjusted conversion ratio between the long-acting ESAs $(n=9)$ was $0.89 \mu \mathrm{g}$ CERA to $1 \mu \mathrm{g}$ darbepoetin (IQR $0.65-$ $1.51)$.

Distributions of achieved hemoglobin levels by ESA type are shown in Figure 4. Observed mean and quartile values (25th, median, 75th) were very similar by ESA type: $11.1,10.4,11.2$, and $11.9 \mathrm{~g} / \mathrm{dL}$ for darbepoetin alfa; $11.2,10.5,11.2$, and $11.9 \mathrm{~g} / \mathrm{dL}$ for CERA; $11.1,10.3,11.2$, and $12.0 \mathrm{~g} / \mathrm{dL}$ for epoetin alfa; and 11.1, 10.3, 11.2, and $11.9 \mathrm{~g} / \mathrm{dL}$ for epoetin beta. No differences in the unadjusted distributions of hemoglobin values by ESA type were detected using Kolmogorov-Smirnov statistics. 
Fig. 3. Patient ESA dosing frequency at DOPPS 5 study entry, by ESA type. The IQR (25th-75th percentiles) for study entry date was May 2012 through October 2013. Epo- $\alpha$ includes biosimilars regulated by the EMA and other copies not authorized by the EMA. EMA, European Medicines Agency; ESA, erythropoiesis-stimulating agent; IQR, interquartile range; DOPPS, Dialysis Outcomes and Practice Patterns Study; CERA, continuous erythropoietin receptor agonist (methoxy polyethylene glycol-epoetin $\beta$ ).

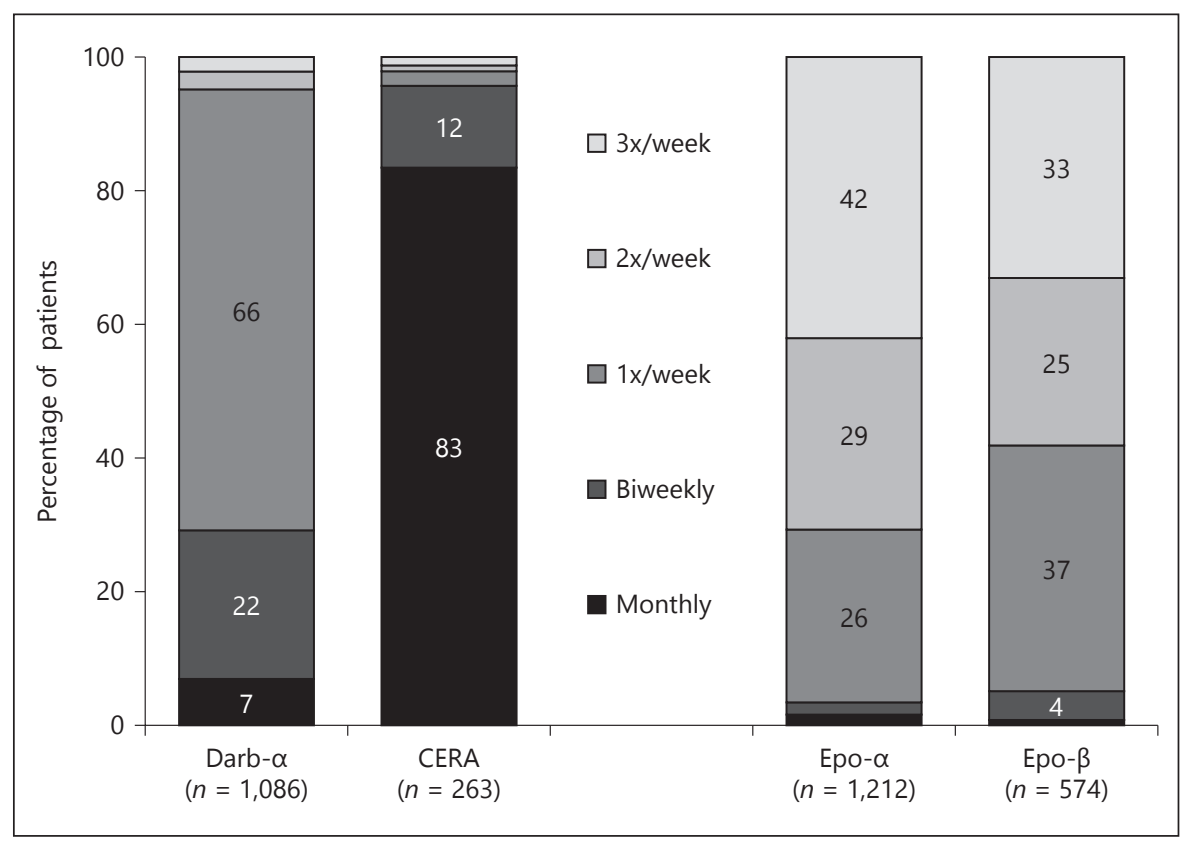

Table 1. ESA dose distribution at DOPPS 5 study entry, by ESA type and route

\begin{tabular}{|c|c|c|c|c|c|c|c|}
\hline \multirow[t]{2}{*}{ ESA Type } & \multirow[t]{2}{*}{$n$} & \multirow[t]{2}{*}{ Mean } & \multicolumn{5}{|c|}{ Percentile } \\
\hline & & & 10 th & 25 th & 50 th & 75 th & 90th \\
\hline Darbepoetin alfa, $\mu \mathrm{g} /$ month & 996 & 171 & 35 & 64 & 121 & 211 & 342 \\
\hline CERA, $\mu \mathrm{g} /$ month & 239 & 158 & 37 & 69 & 109 & 165 & 300 \\
\hline \multicolumn{8}{|l|}{ Epoetin alfa*, units/week } \\
\hline Intravenous & 943 & 8,699 & 1,824 & 3,718 & 5,841 & 10,573 & 17,053 \\
\hline Subcutaneous & 177 & 6,209 & 1,701 & 2,504 & 5,156 & 6,861 & 11,371 \\
\hline \multicolumn{8}{|l|}{ Epoetin beta, units/week } \\
\hline Intravenous & 310 & 8,995 & 1,737 & 3,528 & 5,618 & 10,335 & 17,222 \\
\hline Subcutaneous & 209 & 5,716 & 1,615 & 3,027 & 5,102 & 5,865 & 9,715 \\
\hline
\end{tabular}

* Epoetin alfa includes biosimilars regulated by the EMA and other copies not authorized by the European Medicines Agency.

The interquartile range (25th-75th percentiles) for study entry date was May 2012 through October 2013.

ESA, erythropoiesis-stimulating agent; DOPPS, Dialysis Outcomes and Practice Patterns Study; CERA, continuous erythropoietin receptor agonist (methoxy polyethylene glycol-epoetin $\beta$ ); EMA, European Medicines Agency.

\section{Discussion}

In this paper, we described the prevalence of ESA practices in Europe using a cross-sectional sample of HD patients in the DOPPS, finding broad variability in the use of different ESA types within individual facilities and countries with no apparent differences in the unadjusted distribution of achieved hemoglobin levels.
European ESA practice is rather diverse, with many facilities using multiple ESA options. To wit, we observed that nearly $70 \%$ of European facilities use more than 1 ESA type, and nearly $30 \%$ use 3 or more. Comparative studies of established ESA products have generally been unable to detect substantial differences in efficacy or safety outcomes [11-13]. The decision to use 1 ESA over another can thus be summarized by several other factors: chiefly cost, availability, and preferences for dosing fre- 
Fig. 4. Patient achieved hemoglobin levels at DOPPS 5 study entry, by ESA type. The interquartile range (25th-75th percentiles) for study entry date was May 2012 through October 2013. Epo- $\alpha$ includes biosimilars regulated by the EMA and other copies not authorized by the EMA. EMA, European Medicines Agency; ESA, erythropoiesisstimulating agent; DOPPS, Dialysis Outcomes and Practice Patterns Study; CERA, continuous erythropoietin receptor agonist (methoxy polyethylene glycol-epoetin $\beta)$.

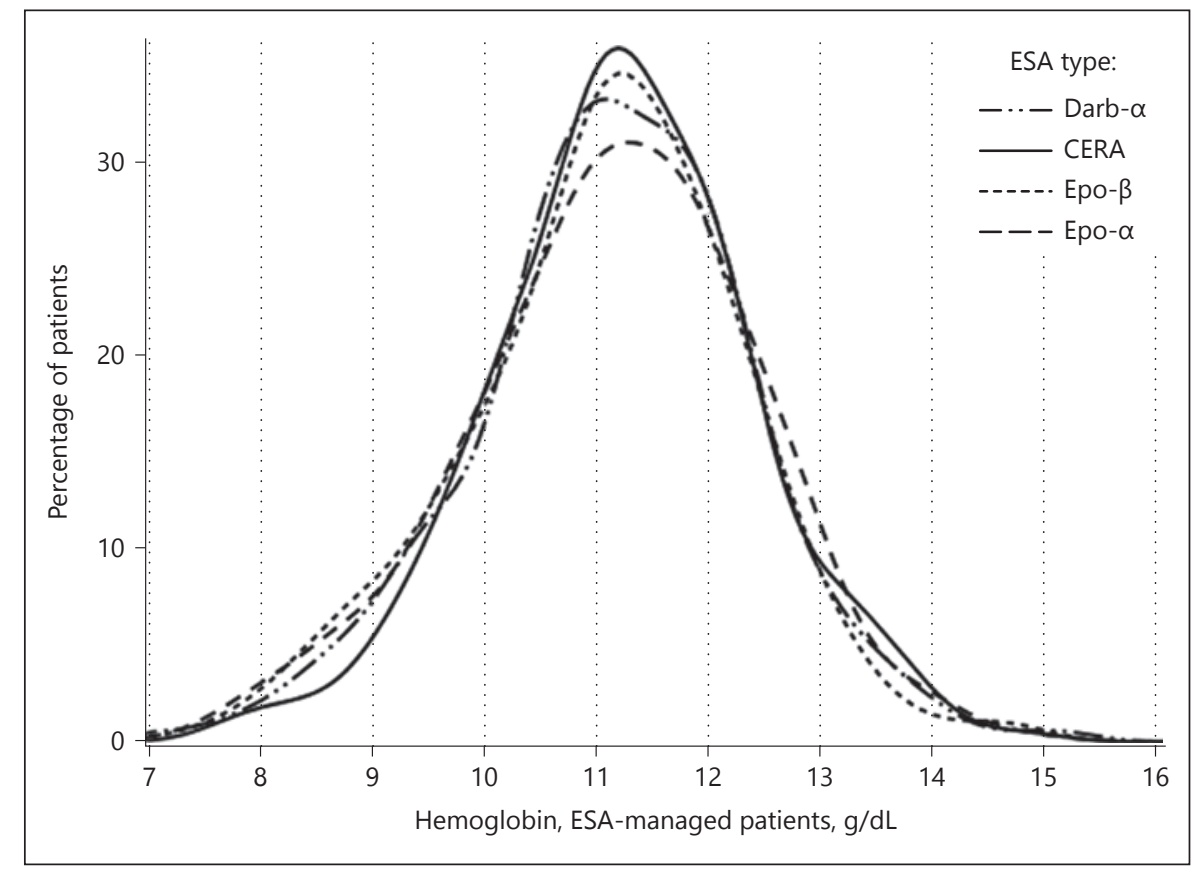

quency [14]. Since the conversion ratios between epoetin alfa and darbepoetin alfa increase at higher doses [5], some nephrologists may also prefer to use long-acting ESAs in hyporesponsive patients to avoid excessively high doses of short-acting epoetin alfa. Use of long-acting ESAs also reduces the frequency of administration, which may be important for (1) reducing the plasma peak of ESAs, possibly associated with side effects, (2) limiting the nurses' burden in injecting the patients at the end of HD when they are very busy, and (3) reducing the need for refrigerators to stock larger amounts of ESAs. Additional considerations, such as providing continuity of care for patients during periods of medical transition [15] (e.g., from chronic kidney disease to HD) and location of manufacturing plants, may also influence regional, intrafacility, and inter-country heterogeneity of ESA types.

We observed remarkably similar distributions of achieved hemoglobin levels across ESA types. As this was not a study of ESA efficacy, we did not attempt to adjust hemoglobin levels for ESA dose or use of iron supplementation. However, most clinicians would be "treating to target" with whatever product they have available, in accordance with established recommendations [16]. We acknowledge as a limitation that the DOPPS 5 surveys did not distinguish ESA biosimilars regulated by the EMA, and other copies not authorized by the EMA, from their originator drugs. Several studies of European HD patients have suggested that higher biosimilar ESA doses (as much as $40 \%$ higher) may be necessary to maintain similar hemoglobin levels, compared to originator products $[17,18]$. However, biosimilars approved by the EMA are required to demonstrate safety and efficacy profiles comparable to the originator biologic drug [19]. Prescribing quotas, tender/reimbursement schemes, and other policy mechanisms to promote the use of biosimilars in Europe vary by country $[20,21]$ and thus may also influence the availability and relative pricing of certain ESA types as described in our study.

ESA product conversions were very uncommon in our study ( $<1 \%$ of patients with $6+$ months of follow-up). The estimated dose conversion ratios between short-acting ESA types and darbepoetin alfa in our analysis were in line with other experimental and observational studies. Suggested dose conversions between epoetin alfa and darbepoetin alfa vary according to baseline, or pre-conversion, level [5], and the conversion factor typically is higher at higher baseline dose levels. Our median estimated conversion factor of 206 (iv) epoetin units to $1 \mu \mathrm{g}$ darbepoetin alfa falls within the range of plausible values previously reported in the literature [22-24]. Recommended dose conversion ratios for CERA have not been provided by the manufacturer, but a multicenter observational study of HD patients who converted from darbepoetin alfa to CERA estimated a mean dose conversion ratio of 1.21 [25]. Our observed median conversion ratio of 0.89 was based on only 9 observed conversions from 
darbepoetin alfa to CERA and should not be viewed as authoritative. On the other hand, the lower conversion ratio for CERA is internally consistent with the observational data collected in this study, where monthly CERA dose is approximately $10 \%$ lower than for darbepoetin alfa (median, 109 vs. $121 \mu \mathrm{g} /$ month; mean, 158 vs. $171 \mu \mathrm{g} /$ month; Table 1). Our study did not capture the reasons for within-patient switching of ESA types. However, we speculate that, due to absence of any particular medical indication for doing so, physicians are hesitant to use an alternative ESA once a patient has established tolerance and effectiveness with a given ESA for legal, ethical, or other reasons (i.e., raising risk of immunogenicity). Thus, the mixture of ESAs used within a given facility may, to an extent, reflect the mixture of dialysis vintage (i.e., years on dialysis) and medical status of patients within the facility.

A strength of our study is its use of stratified random sampling of dialysis units within each study country, thereby allowing broad generalizability of study findings within those countries. Although the DOPPS uses a randomized sampling design, the facility sample may not capture all regional variations within a country that could affect the types of ESAs available to clinicians.

In summary, a variety of short-acting (such as epoetin alfa and epoetin beta) and long-acting (such as darbepoetin alfa and CERA) ESAs are commonly used in European HD facilities to treat anemia. Only onethird of facilities in the 9 DOPPS European countries used a single ESA for their patients, whereas $30 \%$ of facilities used either 3 or 4 different ESA types for managing anemia within each facility. The availability of these numerous ESA options for managing anemia has allowed European care providers to use the type of ESA best suited for optimizing anemia management according to the particular circumstances of each patient when not greatly limited by local reimbursement policies.

\section{Acknowledgments}

The authors thank Jennifer McCready-Maynes at Arbor Research Collaborative for Health for providing editorial assistance.

\section{Statement of Ethics}

The DOPPS maintains ethics committee approvals in all participating countries, and informed consent was collected from all selected study patients.

ESA Patterns Used in Europe

\section{Disclosure Statement}

Funding for this study was provided by F. Hoffmann-La Roche without restrictions on content. D.S.F., R.L.P., and B.M.R. declare no conflicts of interest. F.L. is or was a member of an advisory board of Akebia, Amgen, Astellas, and Vifor Fresenius Pharma and was a speaker at a meeting supported by Amgen, Astra Zeneca, Roche, and Vifor Fresenius Pharma.

The DOPPS Program is funded by a consortium of private industry, public funders, and professional societies. Funding is paid to Arbor Research Collaborative for Health and not to individual investigators. Principal funders: Amgen, Kyowa Hakko Kirin, and Baxter Healthcare. Additional support for specific DOPPS projects and/or program activities in specific countries was provided by Amgen, Association of German Nephrology Centres (Verband Deutsche Nierenzentren e.V.), AstraZeneca, European Renal Association-European Dialysis and Transplant Association (ERA-EDTA), German Society of Nephrology (DGfN), Hexal AG, Janssen, Japanese Society for Peritoneal Dialysis (JSPD), Keryx, Proteon, Relypsa, Roche, Societa Italiana di Nefrologia (SIN), Spanish Society of Nephrology, and Vifor Fresenius Medical Care Renal Pharma. Public funding and support is provided for specific DOPPS projects, ancillary studies, or affiliated research projects by - Australia: National Health and Medical Research Council (NHMRC); Canada: Canadian Institutes of Health Research (CIHR) and Ontario Renal Network; France: Agence Nationale de la Recherche; Thailand: Thailand Research Foundation (TRF), Chulalongkorn University Matching Fund, King Chulalongkorn Memorial Hospital Matching Fund, and the National Research Council of Thailand (NRCT); United Kingdom: National Institute for Health Research (NIHR) via the Comprehensive Clinical Research Network (CCRN); and United States: National Institutes of Health (NIH) and Patient-Centered Outcomes Research Institute (PCORI). All support is provided without restrictions on publications.

References

1 National Kidney Foundation: KDOQI clinical practice guidelines and clinical practice recommendations for anemia in chronic kidney disease. Am J Kidney Dis 2006;47(suppl 3):S11-S145.

2 Janssen-Cilag: Eprex Product Information http://www.janssen.com/australia/sites/ www_janssen_com_australia/files/prod_ files/live/eprex_pi.pdf (accessed January 15, 2017).

3 European Medicines Agency. NeoRecormon (Epoetin Beta) Product Information. http:// www.ema.europa.eu/docs/en_GB/document_library/EPAR_-_Product_Information/human/000116/WC500024979.pdf (accessed January 15, 2017).

4 Report from the Commission to the Council on the Activities of the Committee for Proprietary Medicinal Products. COM (91) 39 final, February 15, 1991. http://aei.pitt. edu/4754/1/4754.pdf (accessed March 8, 2018). 
5 European Medicines Agency. Aranesp Product Information. http://www.ema.europa.eu/ docs/en_GB/document_library/EPAR_-_ Product_Information/human/000332/ WC500026149.pdf (accessed January 15, 2017).

6 European Medicines Agency. Mircera Product Information. http://www.ema.europa.eu/ docs/en_GB/document_library/EPAR_-_ Product_Information/human/000739/ WC500033672.pdf (accessed January 15, 2017).

7 Mikhail A, Farouk M: Epoetin biosimilars in Europe: five years on. Adv Ther 2013;30:2840.

8 Young EW, Goodkin DA, Mapes DL, Port FK, Keen ML, Chen K, Maroni BL, Wolfe RA, Held PJ: The dialysis outcomes and practice patterns study (DOPPS): an international hemodialysis study. Kidney Int 2000;57(suppl 74):S74-S81.

9 Pisoni RL, Young EW, Dykstra DM, Greenwood RN, Hecking E, Gillespie B, Wolfe RA, Goodkin DA, Held PJ: Vascular access use in Europe and the United States: results from the DOPPS. Kidney Int 2002;61:305-316.

10 Robinson B, Fuller D, Zinsser D, Albert J, Gillespie B, Tentori F, Turenne M, Port F, Pisoni $\mathrm{R}$ : The dialysis outcomes and practice patterns study (DOPPS) practice monitor: rationale and methods for an initiative to monitor the new US bundled dialysis payment system. Am J Kidney Dis 2011;57:822-831.

11 Winkelmayer WC, Chang TI, Mitani AA, Wilhelm-Leen ER, Ding V, Chertow GM, Brookhart MA, Goldstein BA: Longer-term outcomes of darbepoetin alfa versus epoetin alfa in patients with ESRD initiating hemodialysis: a quasi-experimental cohort study. Am J Kidney Dis 2015;66:106-113.
12 Abraham I, MacDonald K: Clinical safety of biosimilar recombinant human erythropoietins. Expert Opin Drug Saf 2012;11:819-840.

13 Locatelli F, Choukroun G, Truman M, Wiggenhauser A, Fliser D: Once-monthly continuous erythropoietin receptor activator (C.E.R.A.) in patients with hemodialysis-dependent chronic kidney disease: pooled data from phase III trials. Adv Ther 2016;33:610625.

14 Palmer SC, Saglimbene V, Mavridis D, Salanti G, Craig JC, Tonelli M, Wiebe N, Strippoli GF: Erythropoiesis-stimulating agents for anaemia in adults with chronic kidney disease: a network meta-analysis. Cochrane $\mathrm{Da}$ tabase Syst Rev 2014;12:CD010590.

15 Amara S, Lew I, Adamson RT: Optimizing anemia management through medication reconciliation: applying the 2010 joint commission patient safety goal requirements. P T 2010;35:165-174

16 Locatelli F, Bárány P, Covic A, De Francisco A, Del Vecchio L, Goldsmith D, Hörl W, London G, Vanholder R, Van Biesen W; ERAEDTA ERBP Advisory Board: Kidney disease: improving global outcomes guidelines on anaemia management in chronic kidney disease: a European renal best practice position statement. Nephrol Dial Transplant 2013;28: 1346-1359

17 Hörl WH, Locatelli F, Haag-Weber M, Ode M, Roth K; Epo-PASS Study Group: Prospective multicenter study of HX575 (biosimilar epoetin- $\alpha$ ) in patients with chronic kidney disease applying a target hemoglobin of 10-12 g/dl. Clin Nephrol 2012;78:24-32.

18 Minutolo R, Bolasco P, Chiodini P, Sposini S, Borzumati M, Abaterusso C, Mele AA, Santoro D, Canale V, Santoboni A, Filiberti O, Fiorini F, Mura C, Imperiali P, Borrelli S, Russo L, De Nicola L, Russo D: Effectiveness of switch to erythropoiesis-stimulating agent (ESA) biosimilars versus maintenance of ESA originators in the real-life setting: matchedcontrol study in hemodialysis patients. Clin Drug Investig 2017;37:965-973
19 European Medicines Agency and the European Commission. Biosimilars in the EU: Information Guide for Healthcare Professionals. http://www.ema.europa.eu/docs/en_GB/ document_library/Leaflet/2017/05/ WC500226648.pdf (accessed January 15, 2017).

20 Simon-Kucher: Policy Requirements for a Sustainable Biosimilar Market (September 2016). h t tp:// www. medicinesforeurope. com/2016/09/19/policy-requirements-for-asustainable-biosimilar-market-simon-kucher-2016/ (accessed January 15, 2017).

21 Rémuzat C, Dorey J, Cristeau O, Ionescu D, Radière G, Toumi T: Key drivers for market penetration of biosimilars in Europe. J Mark Access Health Policy 2017;5:1-15.

22 Raymond CB, Wazny LD, Vercaigne LM, Lesperance EM, Skwarchuk DE, Bernstein KN: Conversion from epoetin alfa to darbepoetin alfa within the Manitoba Renal Program: evaluation of dose ratios. CANNT J 2008; 18 39-43.

23 Roger SD, Cooper B: What is the practical conversion dose when changing from epoetin alfa to darbepoetin outside of clinical trials? Nephrology (Carlton) 2004;9:223-228.

24 Bock HA, Hirt-Minkowski P, Brünisholz M, Keusch G, Rey S, von Albertini B; Swiss EFIXNES trial investigators: Darbepoetin alpha in lower-than-equimolar doses maintains haemoglobin levels in stable haemodialysis patients converting from epoetin alpha/beta. Nephrol Dial Transplant 2008;23: 301-308.

25 Choi P, Farouk M, Manamley N, Addison J: Dose conversion ratio in hemodialysis patients switched from darbepoetin alfa to PEGepoetin beta: AFFIRM Study. Adv Ther 2013 30:1007-1017. 